\title{
Grey areas: Formal properties in the perception of sculpture
}

\author{
JEN FULLERTON
}

\section{Abstract}

The focus of this research was to investigate the significance of formal properties in the perception of sculpture. Throughout the project, I considered how qualities such as shape, scale, materiality and positioning could combine to create dynamic and compelling sculptures, when there was no overt content or narrative. Considering the work of artists such as Robert Morris, Anne Truitt and Anish Kapoor, and studying movements and art forms such as Formalism, Minimalism and Installation, led to experiments with several materials and forms before constructing sets of non-representational paper sculptures. The final body of work comprised multiple installations, each containing similar sculptures of various scales, in similar colours and shapes. The differences within, and between, each installation were intended to provide a space for the viewer to perceive, and re-perceive, similar objects in multiple ways.

\section{Introduction}

My focus during this research project was to investigate the significance of formal properties in the perception of sculpture. More specifically, I considered the degree to which qualities such as shape, scale, materiality and positioning could combine to create dynamic and compelling sculptures, when there was no overt content or narrative. My aim is captured in the following question: 'To what degree do a sculpture's formal qualities drive the way it is perceived, without reliance on narrative?' This project has expanded upon a theme I began researching in 2011: selective perception - the unconscious act of seeing only what we choose to see in one another based on our preconceived ideas. ${ }^{1}$ I have widened my investigation to include the perception of objects, specifically sculpture. My interest in the way formal qualities can affect the perception of

1 Wisc-Online, 'Selection: the First Stage in the Perception Process,' accessed October 3, 2011, www.wisconline.com/learn/career-clusters/arts-audio-video-technology-and-communications/oic2901/selection-thefirst-stage-in-the-perception-p. 
sculpture was piqued when I visited Anish Kapoor's exhibition at the Museum of Contemporary Art. ${ }^{2}$ His use of scale and colour in particular led me toward an appreciation of the significance of formal properties and a desire to learn more.

My investigation is comprised of two intertwined parts: theoretical and practical. My theoretical investigation involved gaining an understanding of the way objects, in general, are perceived. This included enquiries into MerleauPonty's views on phenomenology, ${ }^{3}$ as well as Ernst Gombrich ${ }^{4}$ and John Berger's ${ }^{5}$ explanations of the way we view objects. To translate this to the way sculpture is perceived and the importance of formal attributes in driving that perception, I studied the theories of Formalism (that artists should avoid meaning in favour of engagement with formal qualities), ${ }^{6}$ and Minimalism (that work should not reference anything but itself). ${ }^{7}$ I also investigated the work of sculptors such as Robert Morris and Anne Truitt, relevant to my research because of the importance of the formal aspects of their work. Another area of research was an analysis of Installation art, to understand the significance of formal spatial qualities on the perception of sculpture - how a work's positioning in a gallery space could affect the way it is perceived.

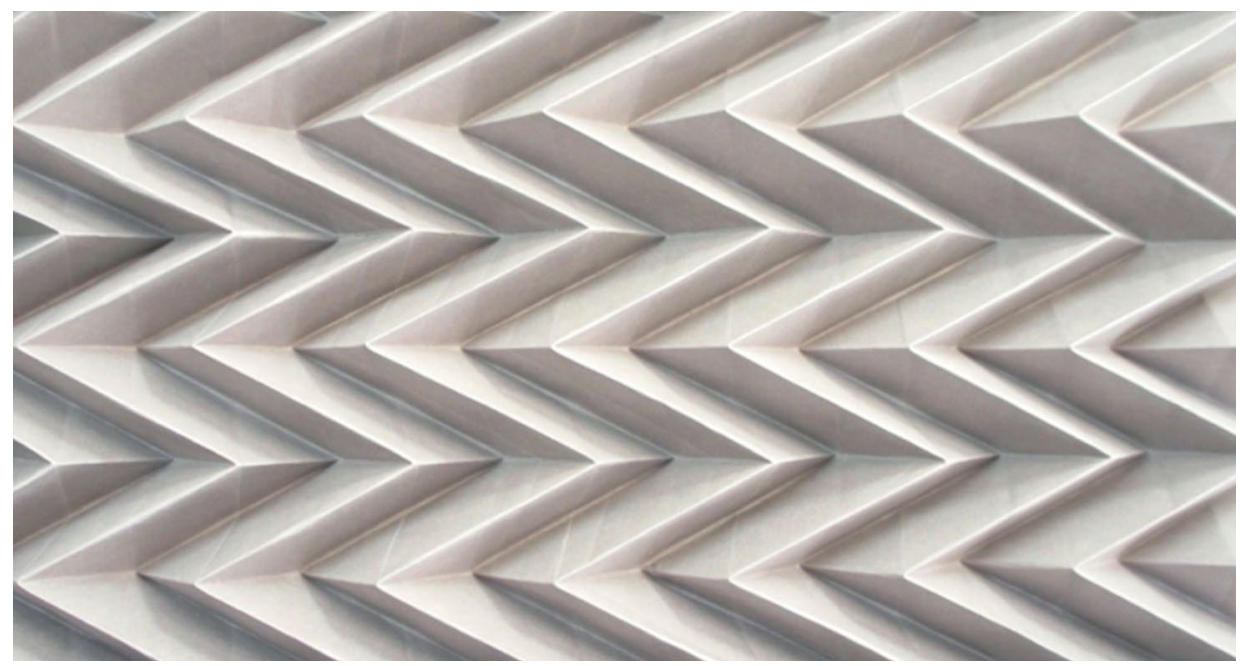

Figure 1. Paper folding experiment, 2013.

Photo: Jen Fullerton.

2 Anish Kapoor, 'Anish Kapoor,' Exhibited at: Museum of Contemporary Art Australia, December 20, 2012 - April 1, 2013.

3 Bernard Flynn, 'Maurice Merleau-Ponty', in The Stanford Encyclopedia of Philosophy, ed. Edward N. Zalta (Fall 2011 Edition), accessed October 6, 2013, plato.stanford.edu/archives/fall2011/entries/merleau-ponty/.

4 Ernst H. Gombrich, Art and Illusion - A Study in the Psychology of Pictorial Representation, 6th Ed. (London: Phaidon Press Ltd, 2002).

5 John Berger, Ways of Seeing (London: Penguin, 1972).

6 Anne D'Alleva, Methods and Theories of Art History (London: Laurence King Publishing Ltd, 2012), $16-17$.

7 Ibid., 16-17. 
The work I produced during this project was informed by paper artist Paul Jackson's book, Folding Techniques for Designers from Sheet to Form. ${ }^{8}$ I began by learning and following Jackson's techniques, moving on to develop my own original designs. Another informative text was Stephen Luecking's Principles of Three-Dimensional Design ${ }^{9}$ - a constant reference regarding the formal aspects of my work. I began my practical and material investigation by constructing many and varied sculptural objects from paper, porcelain, lead and aluminium. After seeking feedback on the objects, I settled on creating only folded paper sculptures, keeping them deliberately non-representational to minimise the chance of viewers perceiving them as recognisable 'things', and applying preconceptions about what each sculpture meant rather than purely considering what they saw in each form: for example, scale, colour or materiality. This approach, combined with the inclusion of obvious contrasts of formal qualities between sculptures, allowed more scope for formal qualities to drive perceptions.
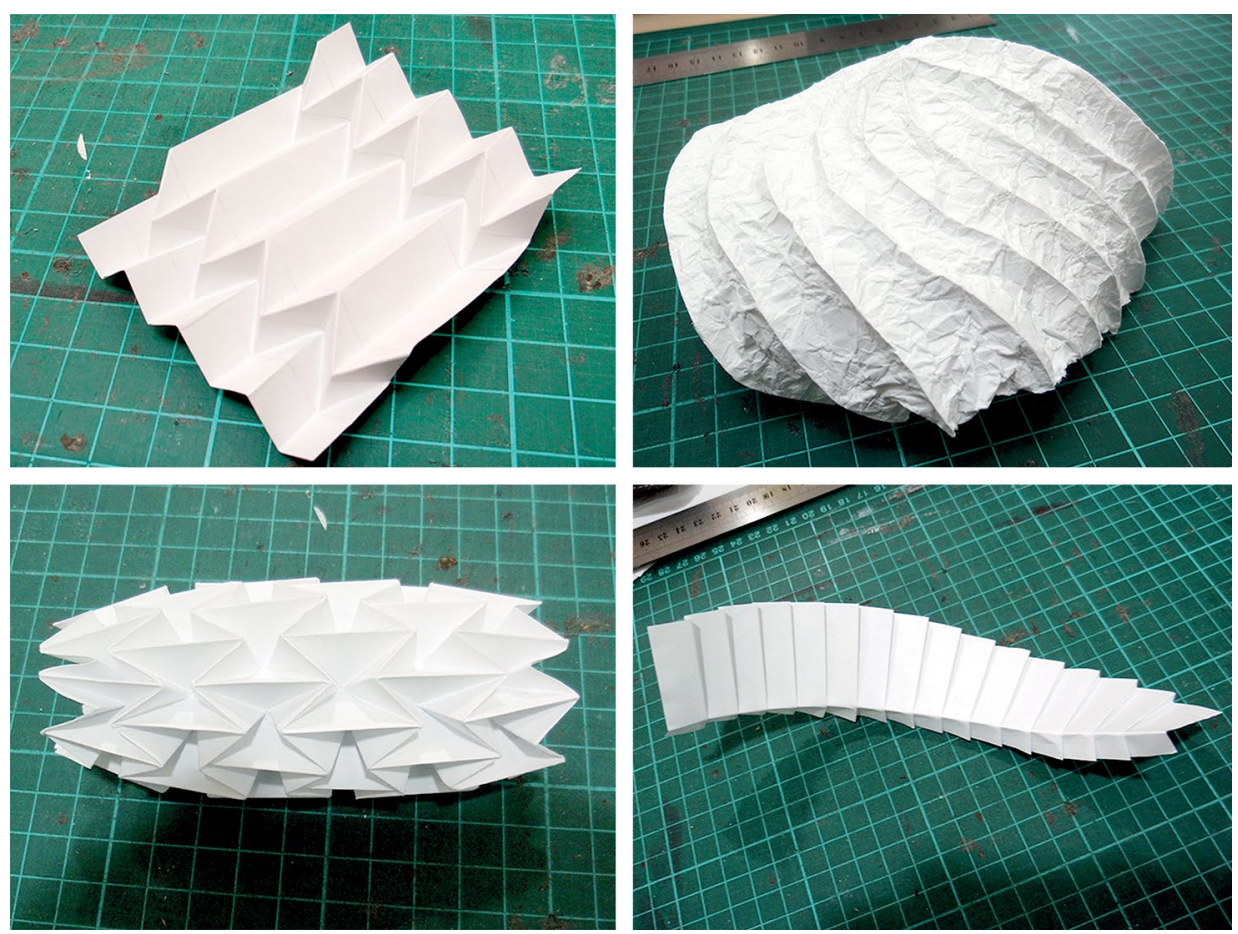

Figure 2. Paper folding experiments, 2013.

Photo: Jen Fullerton.

8 Paul Jackson, Folding Techniques for Designers from Sheet to Form (London: Laurence King Publishing Ltd, 2011).

9 Stephen Luecking, Principles of Three-Dimensional Design (New Jersey: Pearson Education, 2002). 
In this exegesis, I discuss some background to the perception of objects, my examination of some of the art movements that emphasise a reliance on formal aspects to drive perception, and my examination of the work of other artists to whom consideration of formal properties is of the utmost importance. This is followed by a discussion of my own work, including an explanation of my material investigation, the work this led me to create, and the decisions I made before settling upon my final body of work. Finally, I discuss the resulting body of work - my choice of materials, the formal characteristics of the work and my reasons for altering these qualities from one installation to the next.

\section{Theoretical investigation}

Expectation created illusion. ${ }^{10}$

During my theoretical investigation I studied phenomenology and the perception of objects in general, and examined Formalism, Minimalism and Installation art to explore the way art objects - sculptures - are perceived, specifically when considered in terms of their formal qualities. To directly relate this broader research to my project, I examined the work of several sculptors, paying particular attention to their use of formal qualities to drive perception.

Philosophers and art historians have, at great length, discussed the perception of 'things'. In The Phenomenology of Perception (1945), philosopher Maurice Merleau-Ponty claimed 'the thing is inseparable from a person perceiving it'. Because it sits within our gaze, it becomes 'invested with humanity', causing a relationship to form between viewer and thing. Merleau-Ponty goes on to suggest that we do not just develop an inter-relationship with that thing, but with the world - the world being full of things. ${ }^{11}$ In Ways of Seeing (1972), John Berger posits more simply that we do not look at one thing in isolation we consider what we see in relation to what else we see, what we already know, and ourselves. ${ }^{12}$ For this research project, I wanted to explore not just how 'things' are perceived, but how 'things created as works of art' are perceived. When viewing a sculpture we do not consider it in isolation but compare it to everything else we see at the time and overlay it with our prior experience and knowledge. Ernst Gombrich referred to this as our mental set: 'the attitudes and expectations which will influence our perception and make it ready to see ... one thing rather than another' ${ }^{13}$

10 Gombrich, Art and Illusion, 171

11 Claire Bishop, Installation Art (London: Tate Publishing, 2005), 50.

12 Berger, Ways of Seeing, 9.

13 Gombrich, Art and Illusion, 157. 
A common expectation in our mental set seems to be that works of art should contain some meaning. In her essay Against Interpretation (1966), Susan Sontag stated that there is an assumption that a work of art 'is its content' - that because it is a work of art it must 'say something'. ${ }^{14}$ She claimed, 'Our task is not to find the maximum amount of content in a work of art ... our task is to cut back content so that we can see the thing at all'.$^{15}$ To follow Sontag's line of thinking, works of art should be able to stand on their own without the need of a 'back story'. Marshall McLuhan, in Understanding Media: The Extensions of Man, ${ }^{16}$ declared that people would often ask what a painting was about, but not what a house or a dress was about. McLuhan suggested this was because with objects other than art, the viewer has a sense of 'the whole pattern of form and function as a unity' ${ }^{17}$ The formal qualities of an artwork, then - the way it looks, what it is made of and how it sits in a space - should be able to work in unity to drive perception. My material investigations support this idea through my creation of deliberately non-representational sculptures, relying on formal aspects alone to direct perception - a Formalist approach.

Formalists believe context or meaning should be rejected in favour of direct engagement with the formal qualities of a work (for example, shape, material and scale). ${ }^{18}$ Many art historians, writers and critics have echoed this view - in fact, Formalism is as much a form of critique as a form of art itself. Henri Focillon (1881-1943), for example, saw art objects as 'living entities that evolved and changed over time according to the nature of their materials and their spatial setting ${ }^{\prime}{ }^{19}$ Clement Greenberg (1909-1994) stated that the subject of art was art itself, ${ }^{20}$ and Rosalind Krauss (1941- ) contended that Picasso's collages, in particular, rejected representation; they displayed, purely through their formal qualities, the 'absence of actual presence'. She labelled this phenomenon 'material philosophy'. ${ }^{21}$ Minimalists have a similar view: Minimalist art generally has no content, referring only to itself and the fact that it exists in the world, leaving the viewer to focus on the work's formal characteristics. ${ }^{22}$ It often uses repeated forms presented in a way designed to activate the viewer through direct engagement; creating 'environments' that inspire the viewer to walk

14 Susan Sontag, 'Against Interpretation', in Against Interpretation and Other Essays (New York: Farrar, Straus \& Giroux, 1966).

15 Ibid., 9.

16 Marshall McLuhan, Understanding Media: The Extensions of Man (London: Sphere Books, 1972).

17 Ibid., 21.

18 D'Alleva, Methods and Theories of Art History, 16-17.

19 Ibid., 17-18.

20 Ibid., 18.

21 Ibid., 19.

22 James Meyer, Minimalism. (London: Phaidon Press Ltd, 2010), 15. 
around and examine objects from different viewpoints. ${ }^{23}$ According to Claire Bishop, this leaves the viewer contemplating not just the work itself, but the space in which the work is presented and the very act of perceiving the work. ${ }^{24}$

Deliberate consideration of the gallery space and the viewer's physical point of view is also important to Installation art. In an installation, the viewer shifts from the role of external observer to that of participant. They move through the work rather than around it, and experience the work and the space on a bodily level as well as a visual one. ${ }^{25}$ Bishop reiterates this view, suggesting that Installation art is experienced on a phenomenological level. It no longer considers the viewer as a pair of 'disembodied eyes', but as an 'embodied viewer' whose other senses are as important to the perception of the work as their vision. ${ }^{26}$ For the purposes of this research project, I considered space and placement - the installation of sculpture - to be formal properties as much as colour and shape. The formal properties I examined include:

- line and plane;

- shape, form and proportion;

- scale and volume;

- colour, texture and materiality;

- space (both that occupied by the sculpture and the negative space that surrounds it); and

- position and placement.

My interest in the formal qualities of sculpture was piqued when I visited Anish Kapoor's exhibition at the Museum of Contemporary Art. ${ }^{27}$ While there is clearly a spiritual element to Kapoor's work, I was drawn to his use of scale, colour and placement to challenge perceptions. ${ }^{28}$ Sky Mirror (2006), for example, is of a grandiose scale leading to a potentially disorienting experience, as we appear to view the sky on the ground. The work has no colour of its own as it is designed to mirror the sky. Placement, then, becomes an extremely important element in this work - if it were displayed inside a gallery, we would see a far less interesting reflection of the gallery's ceiling.

Kapoor contrasts work such as this with densely coloured work of a smaller scale, for example The Oracle (1990-2002). In this work, the matt black interior of the space carved into the rock reflects no light at all, leaving the viewer

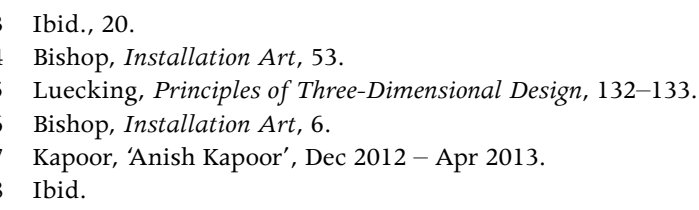


wondering if they see a hole or a flat black surface. I found Kapoor's work extremely compelling and was inspired to discover whether I, too, could make work that was so engaging due to its formal qualities. But Kapoor took his work with perception further than I chose to for this project. Much of his work relies on optical illusion - is a work flat or deep, is it concave or convex? I wanted to create work that could be appreciated on a simpler level - work that, through formal properties alone, said, 'I am what I am', rather than creating an illusion. This realisation led me to look to other artists for inspiration.

I found a clear example of the way formal properties can affect the perception of sculpture in Robert Morris' Untitled (L-Beams) (1965-67). The work comprised three identical L-Beams, each resting on the floor in a different way, each seen from a different angle, in different levels of light and shadow. Purely through the positioning of the three objects, the work became quite dynamic. Although the L-Beams were identical, viewers perceived each to be different to its counterparts. ${ }^{29}$ Rosalind Krauss commented in Passages in Modern Sculpture (1977) that no matter how surely the viewer knew the three L-Beams were the same, it was impossible to see them that way - logic was defeated by perception. ${ }^{30}$ This work is more overt than Kapoor's; Morris has relied purely on placement, and on the negative space around the L-Beams, to drive the perception of the work.

Anne Truitt's A Wall for Apricots (1968) is an example of many similar works she created - an installation of tall, regular columns painted with stripes of colour. Reviewers describe the works as 'giving mass and volume to colour', ${ }^{31}$ and being so human-scale that they 'are sociable and keep you company'. ${ }^{32}$ The primary formal qualities responsible for the perception of these works are colour, proportion, repetition and scale. The colour defines them and gives them visual interest, the repetition of shape, proportion and equally spaced placement creates a sense of unity, while their scale accounts for the bodily response that makes them perhaps feel figurative. The use of repetition and scale has also been an important part of my material investigation - I have created sets of similar sculptures at different sizes, repeating colour, proportion and placement throughout the work.

In the 1980s, Gwyn Hanssen Pigott made an observation about the perception of art and craft - realising that people were making distinctions between functional pottery (considering it craft), and conceptual pottery (considered art).

\footnotetext{
29 Meyer, Minimalism, 82.

30 Bishop, Installation Art, 53-54.

31 Lance Esplund, The Wall Street Journal, December 10, 2009, accessed October 6, 2013, online.wsj.com/ article/ SB10001424052748704782304574542100954055412.html.

32 Blake Gopnik, The Washington Post, October 11, 2009, accessed October 6, 2013, www.washingtonpost. com/wp-dyn/content/story/2009/10/09/ST2009100903235.html?sid=ST2009100903235.
} 
In response to this, she began exhibiting groups of what she called inseparable bowls' to change the way people perceived her work. One bowl on its own had a domestic purpose. A group of bowls exhibited together belonged together as a work of art. The bowls now invited closer inspection, each slightly different in a way that may not have been noticed had they been exhibited separately. ${ }^{33}$ I considered the importance of 'the group' in my material investigations, creating groups of similar sculptures to enhance the differences between them, and I came to understand first-hand the notion of 'inseparability'. While each of my sculptures created its own level of visual interest, that interest could conceivably be over as soon as the piece is viewed. That same sculpture as part of a group, however, maintained interest for longer, with the viewer comparing one piece to another, noting differences in size, colour and shape, and appreciating the way each sculpture in the group related to each of the others.

The work I developed throughout this research project has been in response to this theoretical investigation. As I created each sculpture, I compared it to other sculptures I was making to find the similarities and differences. I remade sculptures in different colours and at different scales to feel the effect of the qualities for myself. I also grouped the sculptures in various ways to determine the effect of placement. I considered the way the sculptures could be perceived placed vertically or horizontally, in large groups and small, in different positions and different levels of light, examining the way each sculpture 'changed' in relation to the others.

\section{Practical investigation}

They are only paper. ${ }^{34}$

To begin my practical, material investigation, I constructed various types of sculptures from assorted materials. My experimentation began with paper and expanded to include porcelain, lead and aluminium in an attempt to examine the effect of materiality on the perception of sculpture. Ultimately, I decided that paper on its own could achieve this with more subtlety than a side-byside comparison of materials. I was also drawn to challenge preconceived ideas about paper. Throughout the year, lecturers and visiting artists have often seemed surprised that my final sculptures would be constructed of paper. I have repeatedly been asked, 'Have you thought about making them out of something else?' and, 'Wouldn't it be great if you could make them out of something more

33 Jason Smith, ed. Gwyn Hanssen Pigott: a survey of works 1955-2005 (Melbourne: National Gallery of Victoria, 2005), 30.

34 Rudi Fuchs quoting Donald Judd's explanation of a poor public reaction to his woodcut prints, in Donald Judd, ed. Nicholas Serota (London: Tate Publishing, 2004), 23. 
permanent?' We understand the concept of a sheet of paper - a blank page - as a 'surface' more than as a finished work. We see a sheet of paper as twodimensional, yet it has an almost limitless potential for three-dimensionality. And we think of paper as disposable, opposing the anticipated permanence of the art object. By working only in paper, I lay down that challenge. I made a conscious decision to not trim overlapping edges or attempt to hide seams, to assert that the sculptures are made of sheets of paper, not just the material of paper. I felt that leaving obvious signs that a sculpture was once a sheet of paper provided a clearer reminder of its materiality.

Most of the sculptures I created are grey. As all colours come loaded with cultural and historical meaning, I chose the colour that was, to me, the quietest - a colour that seemed to exude calm and whose personality would not be so powerful as to overpower the sculptures with its own significance. White may seem to an obvious choice, however the 'brightness' of white, and the concept of white as 'pure' seemed likely to overshadow the objects themselves. I also appreciate the concept of 'grey scale' - the scale of values from light to dark. By scaling the colour of my sculptures in such a way, I could appear to have been applying a value to each of them, despite none of them being more or less valuable than any other.

The ideas that I have put forward about paper, and my use of grey, add a level of narrative to the work, however I believe it still 'only references itself', as any potential content is derived from the analysis of formal properties. This does, however, lead me to an interesting discovery I made during this project, reiterating Marshall McLuhan's belief that 'the medium is the message' - that is, that every medium contains some form of content. ${ }^{35}$ My experimentation has led me to understand that wherever the hand of the artist is involved, content will exist on some level. No matter how clearly I set out to work only with formal qualities, I continually and unconsciously imagined meanings around each sculpture and installation - for example, why they were paper; why they were different scales. Also, wherever the eye of the viewer is involved, it appears that content will exist. On encountering my work, people invariably tell me what the sculptures remind them of, adding their own narrative layer to the work. These conflicting ideas added a level of tension to the work and reiterate the title, Grey areas - somewhere between black and white, right and wrong, expected and unexpected. 
Before I decided to make only installations of grey paper sculptures, I had several 'false starts'. Unsure of how to advance my concepts materially, I considered methods I have found satisfying in the past. I developed ideas for books, but sewn-together pages containing text were far too 'story-like' when I wanted to make less narrative works. I then began folding paper, following instructions from various sources, but kept falling into the trap of trying to make something recognisable, against my intention to create non-representational art. Eventually, I decided to progress several types of work: grey folded sculptures, small white sculptures under glass domes, moulded watercolour pieces and self-portraits with collaged sections of folded paper. On reflection, the work under domes was quite static and feedback suggested the domes themselves introduced their own narrative around concepts such as the containment of specimens, adding an unwanted layer of meaning.

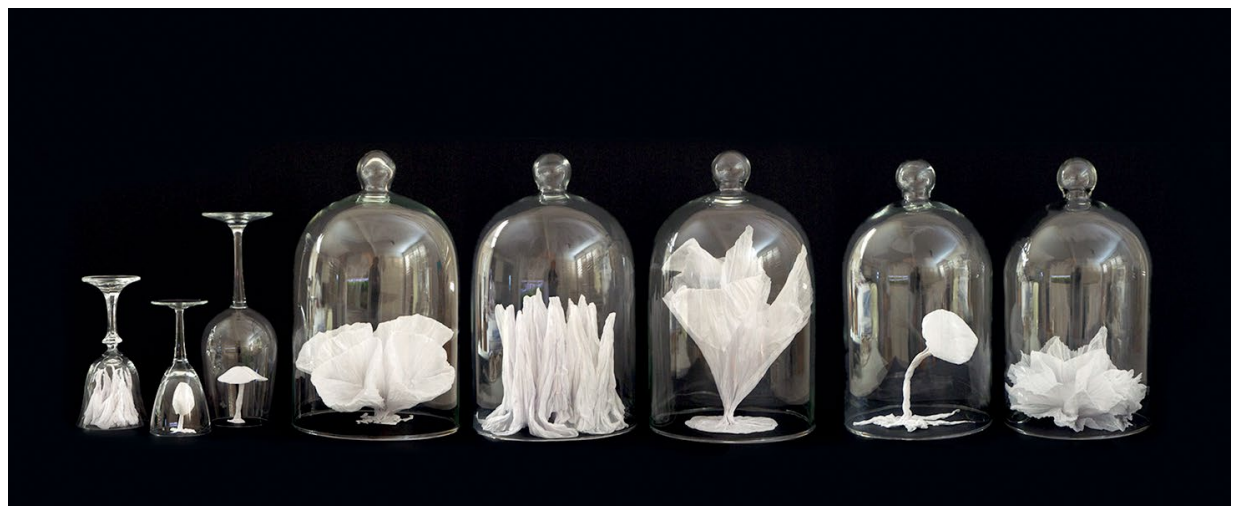

Figure 3. Work under domes, 2013.

Photo: Jen Fullerton.

Feedback around the moulded pieces of watercolour paper consistently suggested that they resembled porcelain, so I made some pieces from porcelain to compare the two materials, and created similar sculptures in aluminium and lead for further comparison. As mentioned earlier, however, I decided that paper on its own spoke about materiality with more subtlety. 


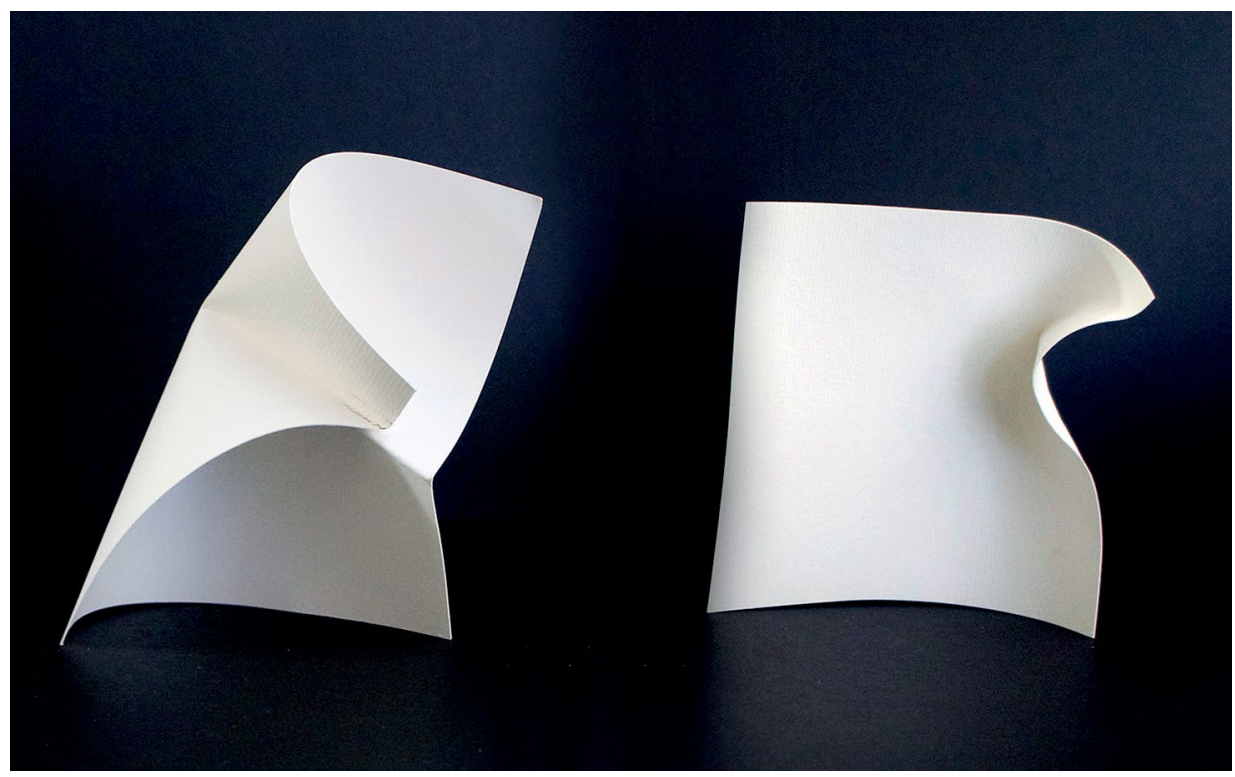

Figure 4. Moulded watercolour paper, 2013.

Photo: Jen Fullerton.
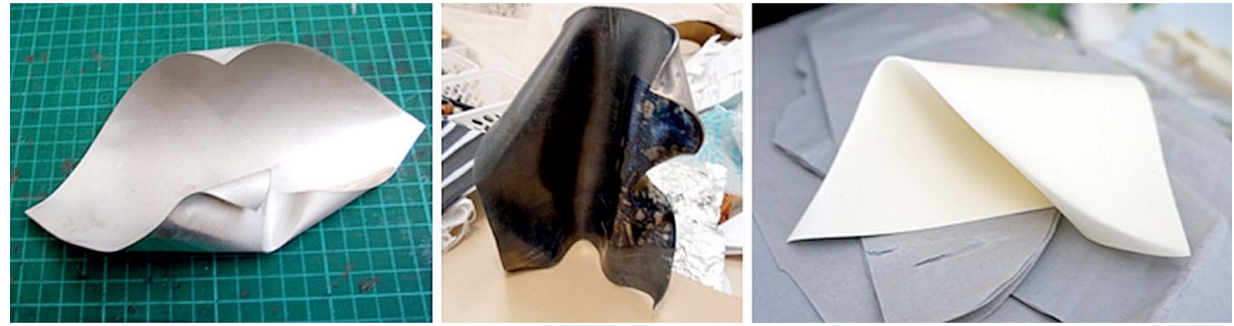

Figure 5. Aluminium, lead and porcelain sculptures, 2013.

Photo: Jen Fullerton.

I then became concerned that presenting groups of work that were so dissimilar - the grey sculptures, domes and moulded sculptures - would not allow formal qualities and presentation to drive perceptions to the same extent as comparing sets of similar sculptures. I continued with my last idea - self-portraits combined with collaged, folded paper - believing that although the collaged elements were similar to the grey sculptures, a tension was created because, in this instance, they disfigured rather than conveyed the beauty of the folded form. However, feedback suggested that the fact that they were quite painterly self-portraits imbued the works with a strong narrative, and that they perhaps did not fit with the other work when I was attempting to produce work that was narrative-free. 


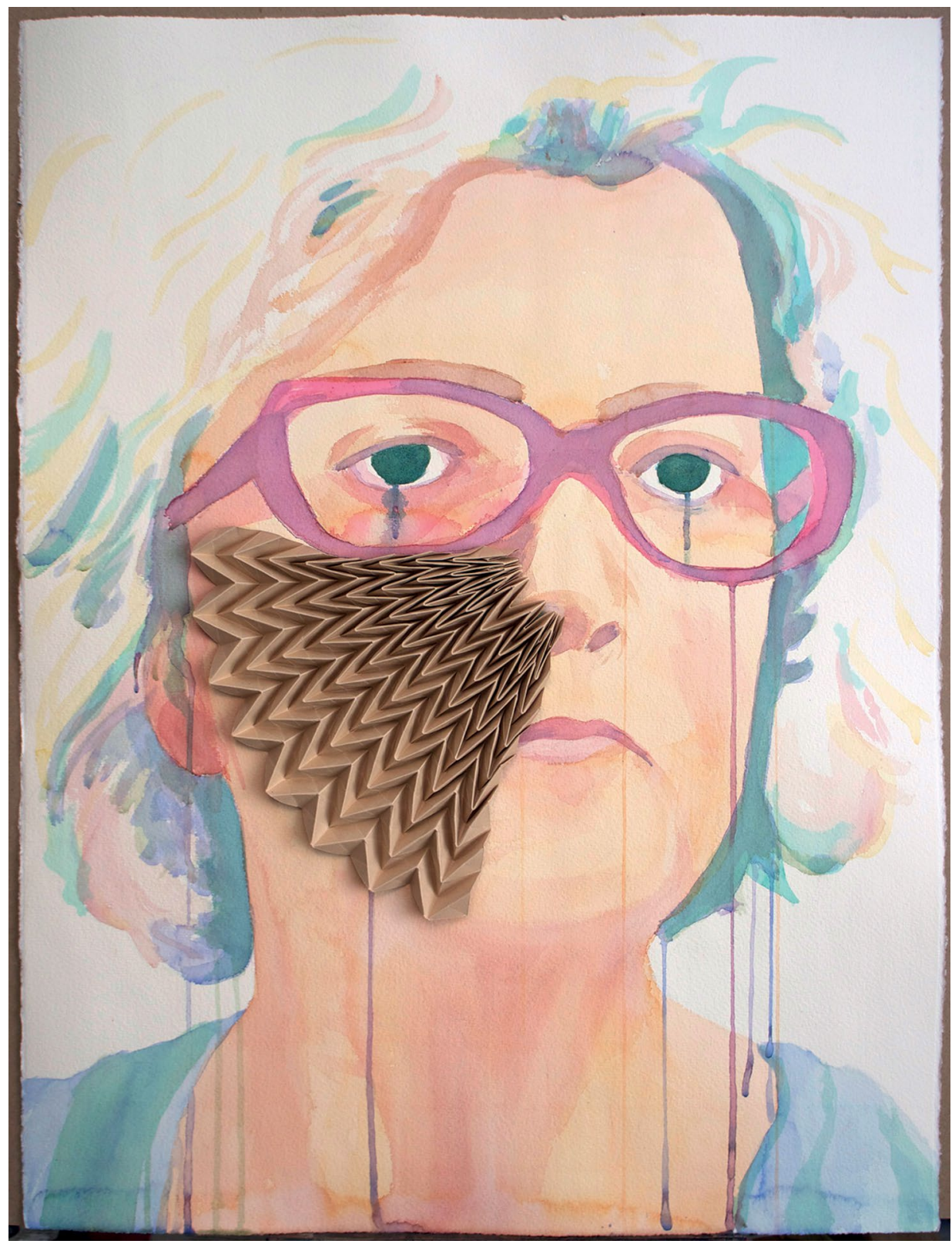

Figure 6. Self-portrait, 2013, watercolour, collage.

Photo: Jen Fullerton.

This feedback led me to re-evaluate the entire body of work, culminating in focusing on only the folded grey sculptures. I kept the sculptures deliberately non-representational to minimise the chance of the viewer perceiving them 
as recognisable 'things', therefore applying preconceptions about what each sculpture meant rather than purely considering what they saw in each form. This allowed more scope for formal qualities to drive perceptions.

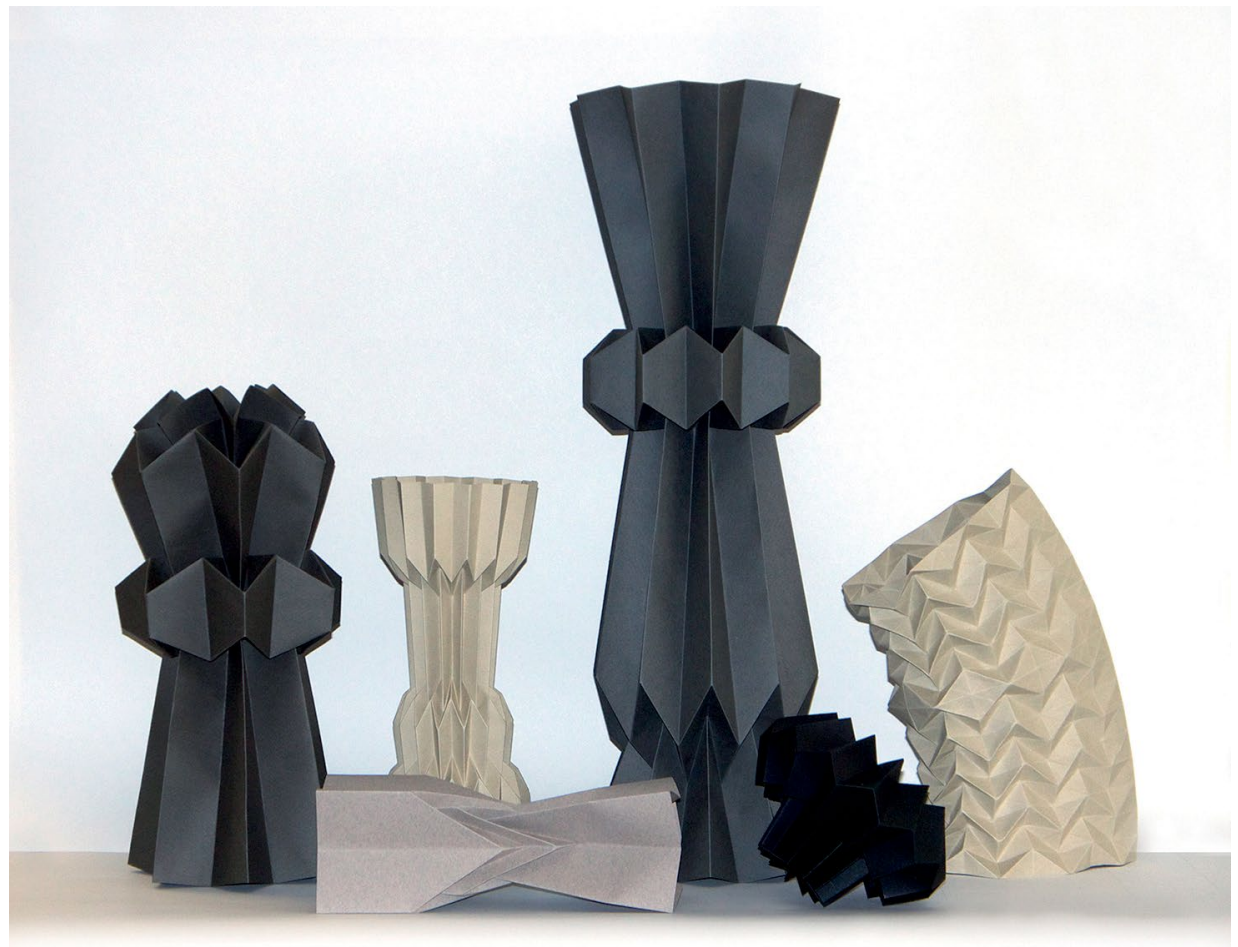

Figure 7. Paper folding experiments, 2013.

Photo: Jen Fullerton.

The sculptures were created from sheets of Canson Mi-Teintes paper which I selected for its material qualities - its texture and strength, the way it folded and held its form, and the way it changed colour in different angles of light. The work contained elements of both Minimalism and Formalism. I took from Minimalism the use of repeated forms and the creation of 'environments', ${ }^{36}$ and drew on Formalism with my lack of overt content - creating sculptures that 'are what they are', with formal qualities driving the work rather than representation or narrative. ${ }^{37}$ The sculptures appeared intensely geometric and may seem to have been based on a mathematical formula. In fact, I learnt from the ANU Applied Mathematics department that the sculptures contained 'auxetics', which can be found in nature and science and do, indeed, have their

36 Meyer, Minimalism, 20.

37 D'Alleva, Methods and Theories of Art History, 16-17. 
own mathematical formula. ${ }^{38}$ I chose not to follow this line of enquiry, however, as I felt that applying such a typology to the sculptures removed some of their inherent mystery and poetry. In the words of Gwyn Hanssen Pigott (speaking about her own work), '[t]hey are only about themselves' ${ }^{39}$

I actually applied very little mathematics to creating the sculptures. I developed the templates by folding each sheet of paper in half and half again until it was divided into 32 vertical sections - the maximum amount of folds each sheet could comfortably hold - maintaining a level of consistency and order throughout the sculptures. I then randomly added rows of diagonal folds to each template, adding an element of difference. (While repetition can create order, too much repetition can become stale. 'Variety is needed to pique attention. ${ }^{40}$ ) By taking this approach, I felt that I was in control of the work I was creating, rather than being governed by an external system such as auxetics.

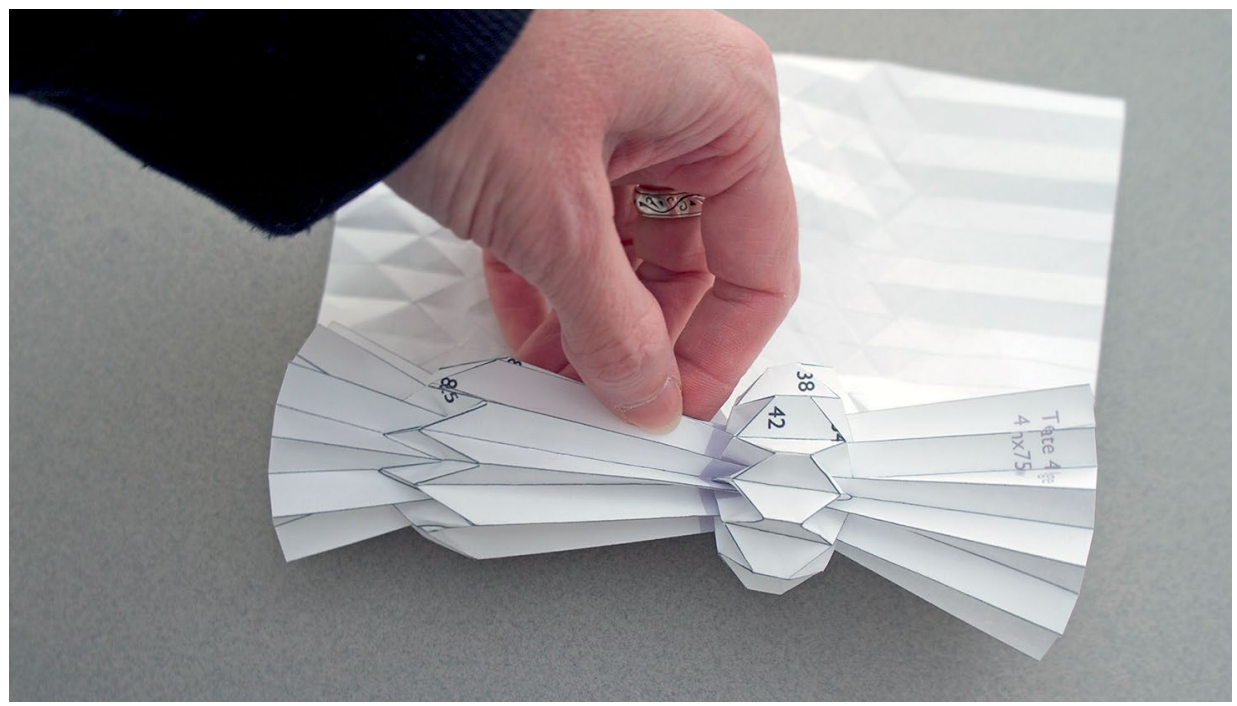

Figure 8. Testing a template, 2013.

Photo: Jen Fullerton.

On encountering the work, one would immediately notice the repetition of lines and angled planes. The angled folds defining the planes gave each of the four original sculptures its identity. ${ }^{41}$ More repetition was involved in the decisions I made about the amount of sculptures, folds and colours. I repeated sets of four sculptures in four shades of grey. The decision to work in multiples of four stems

38 Vanessa Robins, Department of Applied Mathematics, Research School of Physics and Engineering,

The Australian National University, email message to author, June 21, 2013.

39 Smith, Gwyn Hanssen Pigott, 32.

40 Luecking, Principles of Three-Dimensional Design, 41.

41 While there are multiples of each sculpture, they are all developed from the original set of four templates. 
from the abovementioned process of folding a sheet of paper in half and half again. The different shapes, sizes and shades of grey used throughout the work were intended to stir the interest of the viewer, enticing them to appreciate what they saw, rather than seeking a deeper meaning. Pattern, shadow and repetition created a texture across the entire body of work, developing a rhythm for the viewer's eye to follow as they moved from one sculpture, and one installation, to the next. The presentation of each sculpture within its group, as well as the overall design of each installation, was considered in an attempt to maximise the impact of each sculpture as well as the spaces between the sculptures. Spatial principles such as position, direction and scale determined the relationships between each sculpture in a group, as well as the relationship between the group and the space.

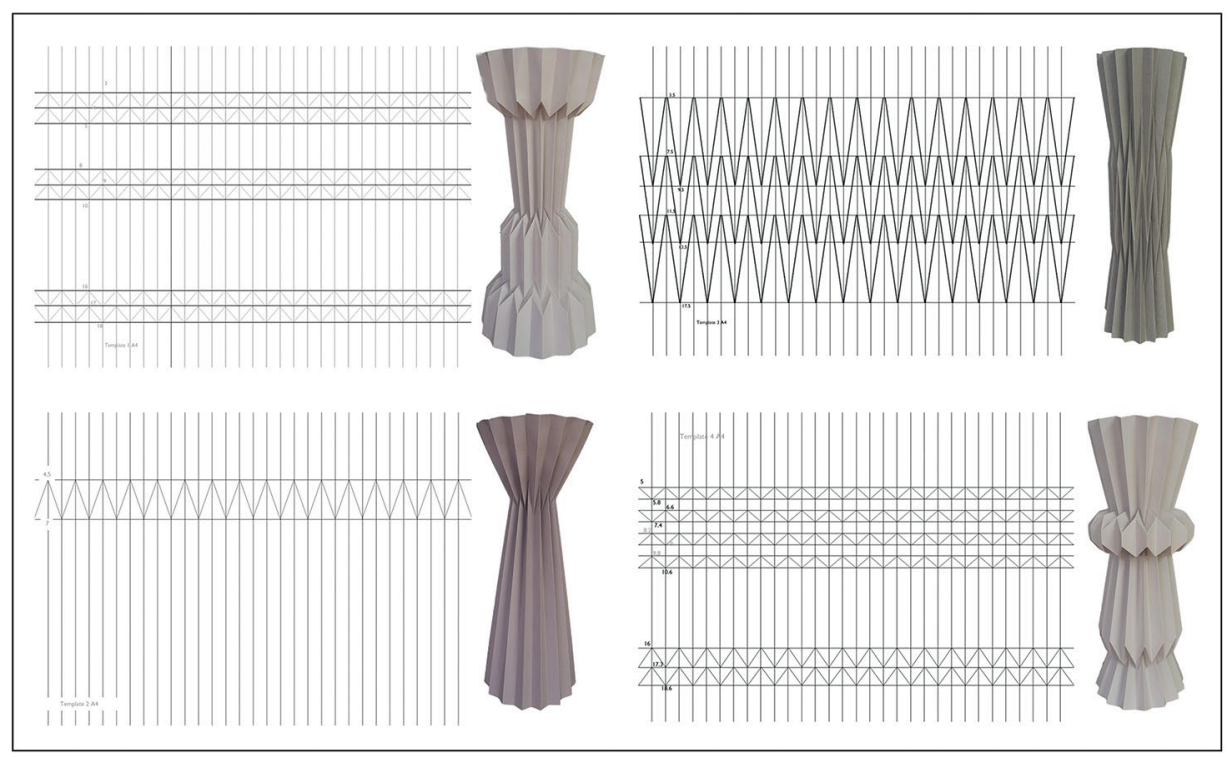

Figure 9. The templates and the sculptures they became, 2013. Photo: Jen Fullerton.

\section{Outcome}

Geometry tempered by poetry. ${ }^{42}$

The final body of work comprised multiple installations, each containing similar sculptures of various scales, in similar colours and shapes. Four original shapes were repeated several times, creating a repetition and consistency that brought

42 Janet Westwood quoting Hanssen Pigott's description of the work of her idols including Morandi, in Smith, Gwyn Hanssen Pigott, 31. 
unity to each group. The installations combined to create a single environment under the title Grey areas, as I felt that the formal qualities of each sculpture and installation were best appreciated when compared to each of the others.

The sculptures seemed almost architectural due to their columnar forms and evoked a bodily reaction when tested with colleagues, as their proportions could cause them to appear figurative. While each sculpture was interesting on its own, I believe that when combined with others in the group, they developed relationships that could change the way they were perceived. My intention in giving the viewer the opportunity to compare similar sculptures at different scales and in different shades of grey was that they would now consider these relationships - the play of large against small, light against dark - as well as the individual sculptures themselves. The materiality of the sculptures was on full display, as some of the sculptures were tall enough that the viewer could examine them in detail. The largest of the sculptures contained an interesting contradiction: being larger, they appeared more solid and grounded yet, at that size, the frailty of the material was more obvious, with the weight of the sculpture starting to bend and warp the paper. One set of sculptures was in miniature scale - vastly different to the others - perhaps drawing the viewer into a more intimate exploration. While the smaller scale may have created a perception of 'safer' or 'friendlier' objects that could be picked up and held by the viewer, this was contradicted by their installation on a plinth, which immediately distanced the sculptures from viewers by announcing them as works of art. The materiality of these sculptures may again have been perceived differently - they were small and delicate, possibly seeming more fragile than the larger sculptures.

The changes to spatial qualities within and between each installation were also very important, potentially raising more questions about relationships in the mind of the viewer, as well as providing a new point of view. While some sculptures sprawled across the gallery floor, others took up space vertically rather than horizontally. The viewer would interact differently with each looking upwards to see some work, or wandering amongst individual sculptures at ground level. The differences in formal qualities within, and between, each sculpture and installation were intended to provide a space for the viewer to perceive, and re-perceive, similar objects in multiple ways. 


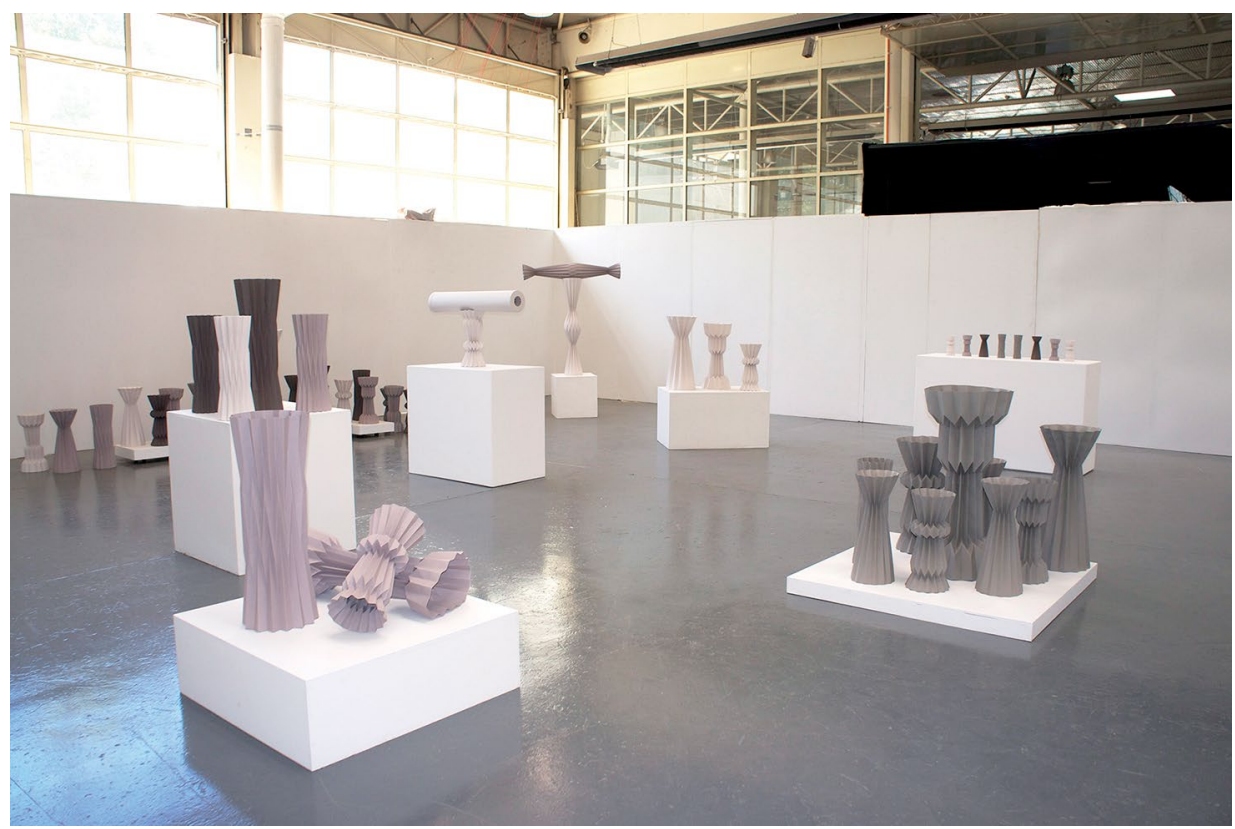

Figure 10. Grey areas, 2013.

Photo: Jen Fullerton.

\section{Conclusion}

In this project, I investigated the significance of formal properties in the perception of sculpture. My research combined an examination of the work of other artists with an interest in formal qualities, the development of a deeper understanding of Formalism, Minimalism and Installation, and the creation of a resolved body of work. My material investigation took me in many directions before I settled upon my final work, as I continually found myself creating work imbued with content - despite specifically setting out to determine the degree to which a sculpture's formal qualities would drive the way it was perceived, with no reliance on content. The final body of work was intended to demonstrate the effect of a sculpture's formal qualities through the presentation of similar, non-representational sculptures reliant upon elements such as shape, scale and materiality rather than overt content. It was also intended to highlight the impact of space and positioning, through the juxtaposition of similar sculptures in various methods of display. During this project, I discovered that wherever the hand of the artist is involved, a level of narrative seems almost unavoidable - I found myself unconsciously imagining meanings around each sculpture and installation that I made. Content also appears unavoidable wherever the eye of the viewer is involved, with most viewers telling me what my sculptures reminded them of, adding their own narrative layer to the work. While both artist and 
viewer seemed to find it difficult not to add their own content to the work, any imagined meaning directly resulted from an analysis of formal qualities. My theoretical and practical investigations have led me to conclude that formal qualities are, indeed, highly significant in the perception of sculpture. Not only do they affect what we see, they also affect what we think we see.

\section{Bibliography}

Berger, John. Ways of Seeing. London: Penguin, 1972.

Bishop, Claire. Installation Art. London: Tate Publishing, 2005.

D'Alleva, Anne. Methods and Theories of Art History. London: Laurence King Publishing Ltd, 2012.

Esplund, Lance. 'Maximal Results, Minimal Means.' The Wall Street Journal. December 10, 2009. Accessed October 6, 2013. online.wsj.com/article/ SB10 001424052748704782304574542100954055412.html.

Flynn, Bernard. 'Maurice Merleau-Ponty.' The Stanford Encyclopedia of Philosophy (Fall 2011 edition). Edited by Edward N. Zalta. Accessed October 6, 2013. plato.stanford.edu/archives/fall2011/entries/ merleau-ponty/.

Gombrich, Ernst. Art and Illusion - A Study in the Psychology of Pictorial Representation, 6th Ed. London: Phaidon Press Ltd, 2002.

Gopnik, Blake. 'Georgetown's Colorful Genius. At the Hirshhorn, Anne Truitt, the Minimalist Who Gave a Little Extra.' The Washington Post. October 11, 2009. Accessed October 6, 2013. www.washingtonpost.com/wp-dyn/ content/story/2009/10/09/ ST2009100903235.html?sid=ST2009100903235.

Jackson, Paul. Folding Techniques for Designers from Sheet to Form. London: Laurence King Publishing Ltd, 2011.

Kapoor, Anish. 'Anish Kapoor.' Exhibited at: Museum of Contemporary Art Australia, December 20, 2012 - April 1, 2013.

Luecking, Stephen. Principles of Three-Dimensional Design. New Jersey: Pearson Education, 2002.

McLuhan, Marshall. Understanding Media: The Extensions of Man. London: Sphere Books, 1972.

Meyer, James. Minimalism. London: Phaidon Press Ltd, 2000 (updated 2010).

Serota, Nicholas, ed. Donald Judd. London: Tate Publishing, 2004. 
Smith, Jason, ed. Gwyn Hanssen Pigott: a survey of works 1955-2005. Melbourne: National Gallery of Victoria, 2005.

Sontag, Susan. 'Against Interpretation'. In Against Interpretation and Other Essays. New York: Farrar, Straus \& Giroux, 1996.

Wisc-Online. 'Selection: the First Stage in the Perception Process.' Accessed October 3, 2011. www.wisc-online.com/learn/career-clusters/arts-audiovideo-technology-and-communications/oic2901/selection-the-first-stage-inthe-perception-p. 
This text is taken from The ANU Undergraduate Research Journal, Volume Six, 2014, edited by Jonathon Zapasnik and Alexandra Hogan, published 2015 by ANU eView, The Australian National University, Canberra, Australia. 